Polymer Journal, Vol. 38, No. 10, pp. 1089-1092 (2006)

(C) 2006 The Society of Polymer Science, Japan

\title{
Equilibrium Melting Temperature of Aliphatic Polyesters Using Model Compounds
}

\author{
Miki OKeda, Yoshihiro Ogawa, ${ }^{\dagger}$ and Naohide Matsumoto \\ Department of Science, Graduate School of Science and Technology, \\ Kumamoto University, Kurokami 860-8555, Japan
}

(Received June 26, 2006; Accepted August 3, 2006; Published September 15, 2006)

\begin{abstract}
A series of oligomers for use as a biodegradable aliphatic polyester model compounds such as poly(dodecamethylene dodecanedioate) (C12-n) and poly(tetradecamethylene tetradecanedioate) (C14-n) were synthesized. C12-n and C14-n were separated by a silica gel column, and pure n-mers were obtained. The melting enthalpies and entropies of $n$-mers were observed to follow a linear equation in terms of $n$. The equilibrium melting temperatures of C12-n and C14-n obtained from $\Delta H / \Delta S$ were $104^{\circ} \mathrm{C}$ and $108^{\circ} \mathrm{C}$, respectively. We can easily calculate the approximate equilibrium melting temperature of aliphatic polyesters $(\mathrm{Cm})$ using $T_{\mathrm{m}}{ }^{0}=411(\mathrm{~m}-2.48) /(\mathrm{m}-1.59)$. [doi:10.1295/polymj.PJ2006064]

KEY WORDS Aliphatic Polyesters / Biodegradable / Equilibrium Melting Temperature / Thermal Properties / Model Compounds /
\end{abstract}

The equilibrium melting temperature $\left(T_{\mathrm{m}}{ }^{0}\right)$, which is different from the melting temperature, is the most important thermal quantity for identifying a given polymer crystal. However, when samples of polymeric materials are differently prepared or treated, they show different degrees of crystallinity, and it is difficult to obtain the equilibrium melting temperature directly from the polymer data. Three methods for obtaining the equilibrium melting temperature of polyethylene have been reported. One is the extrapolation of the melting temperatures of alkanes versus carbon numbers to an infinite molecular weight. The second is the extrapolation of the melting temperature of polymer crystals as a function of the reciprocal lamellar length to an infinite lamellar length (GibbsThomson plot method). The third utilizes a plot of experimental melting temperatures as a function of the crystallization temperature (Hoffman-Weeks plot method). The first method yields a value of 414.3$419.6 \mathrm{~K},{ }^{1-3}$ the second yields a value of $414 \mathrm{~K},{ }^{4}$ and the third a value of $416.6-418.9 \mathrm{~K}^{5}$

$T_{\mathrm{m}}{ }^{0}$ is also important in the study of the mechanism of crystallization, because crystallization phenomena such as lateral growth rate and nucleation rate are controlled by the degree of supercooling $(\Delta T) . \Delta T$ is defined as $\Delta T \equiv T_{\mathrm{m}}{ }^{0}-T_{\mathrm{c}}$, where $T_{\mathrm{c}}$ is the crystallization temperature, the accurate determination of $\Delta T$ depends on the precise measurement of $T_{\mathrm{m}}{ }^{0} \cdot T_{\mathrm{m}}{ }^{0}$ of many polymers have been reported ${ }^{6-10}$ but it is difficult to obtain the precise value of $T_{\mathrm{m}}{ }^{0}$. For example, $T_{\mathrm{m}}{ }^{0}$ of the biodegradable aliphatic polyesters poly(butylene succinate) (PBS) determined by the Gibbs-Thomson and Hoffman-Weeks equations show significant differences for each sample. ${ }^{10}$ From the Gibbs-Thomson equation, the value was $146.5^{\circ} \mathrm{C}$, whereas from the Hoffman-Weeks equation, the value was $127.5^{\circ} \mathrm{C}$. Our research focused on determining the equilibrium melting temperature of aliphatic polyesters using low molecular model compounds. Our previous work had indicated that the equilibrium melting temperature of poly(decamethylene sebacate) consisting of 1,10decanediol and sebacic acid using low molecular model compounds as- $\mathbf{C}_{\mathbf{9}} \mathrm{H}_{\mathbf{1 9}} \mathrm{COO}\left(\mathrm{CH}_{\mathbf{2}}\right)_{10} \mathrm{O}\left[\mathrm{CO}\left(\mathrm{CH}_{2}\right)_{8}\right.$ $\left.\operatorname{COO}\left(\mathrm{CH}_{2}\right)_{10} \mathrm{O}\right]_{\mathbf{n}-1} \mathbf{C O C}_{9} \mathbf{H}_{19}$ was $94{ }^{\circ} \mathrm{C},{ }^{11}$ which was fairly higher than the melting point of the polyester, $73-80^{\circ} \mathrm{C} .{ }^{12}$

In this paper, polyester oligomers comprising repeating units of $-\mathrm{CO}\left(\mathrm{CH}_{2}\right)_{\mathrm{m}-2} \mathrm{COO}\left(\mathrm{CH}_{2}\right)_{\mathrm{m}} \mathrm{O}-(\mathrm{m}=$ $10,12,14)$ and two terminal alkyl groups such as

\section{$\mathrm{C}_{\mathrm{m}-1} \mathrm{H}_{2 \mathrm{~m}-1} \mathrm{COO}\left(\mathrm{CH}_{2}\right)_{\mathrm{m}} \mathrm{O}\left[\mathrm{CO}\left(\mathrm{CH}_{2}\right)_{\mathrm{m}-2} \mathrm{COO}\left(\mathrm{CH}_{2}\right)_{\mathrm{m}} \mathrm{O}\right]_{n-1} \mathrm{COC}_{\mathrm{m}-1} \mathrm{H}_{2 \mathrm{~m}-1}$}

Cm-n $(\mathrm{m}=10,12, \mathrm{n}=1,2,3,4 ; \mathrm{m}=14, \mathrm{n}=1$, $2,3)(\mathrm{Cm}-\mathrm{n}$, where $\mathrm{m}$ is the number of carbon atoms in the chain and $\mathrm{n}$ is the degree of polymerization) were studied as model polyester compounds. Poly- mers with $\mathrm{m} \geqq 10$ were chosen as aliphatic polyesters in this experiment. Kink conformation can be observed in polymers with a low number of methylene groups $;{ }^{13}$ however, extended conformation was postu-

${ }^{\dagger}$ To whom correspondence should be addressed (E-mail: ogawa@aster.sci.kumamoto-u.ac.jp). 
lated for polyesters with long polymethylene sequences. ${ }^{14} \mathrm{~A}$ unit cell of a polyester synthesized from sebacic acid and alkanediol ( $\mathrm{n}=6$ or 12) contains two chain segments with an all-trans conformation and a chain setting angle similar to that reported for polyethylenes. ${ }^{15,16}$ The composition of such polymers is characterized by an alternation of segments of methylene units and ester bonds. The thermal properties of aliphatic polyester n-mers were systematically investigated as a function of the degree of polymerization, and the equilibrium melting temperature was calculated from the data on the enthalpies and entropies of fusion. The relationship between $\mathrm{m}$ and the equilibrium melting temperature is discussed.

\section{EXPERIMENTAL}

\section{Materials}

1,12-Dodecanedioic acid, 1,14-tetradecanedioic acid, 1,12-dodecanediol, 1,14-tetradecamediol, dodecanoic acid, and tetradecanoic acid were purchased from Tokyo Kasei and used without further purification. Other reagents and solvents were commercially available and were also used as received. 1,12-Dodecanedioic acid, 1,12-dodecanediol, and dodecanoic acid in a molar ratio of 2:3:2 to along with a small amount of $p$-toluenesulfonic acid in toluene were boiled under reflux for $24 \mathrm{~h}$. The flask was attached to a water separator equipped with a reflux condenser. A C12-n series mixture was obtained. This mixture was separated and purified at room temperature by using a silica gel column. Toluene was used as an eluent. The mixture can be separated perfectly only at room temperature. C14-4 was insoluble in toluene at room temperature. So we could not obtain C14-4. The results of the elemental analysis of Cm-n are tabulated in Table I. The agreement between the calculated and experimental values is within the usual limit of variation of elemental analysis.

\section{Measurement}

The melting points and thermodynamic properties

Table I. Elemental analysis of model compounds for biodegradable aliphatic polyesters

\begin{tabular}{ccc}
\hline $\mathrm{C} m-\mathrm{n}$ & $\mathrm{C} \%$ & $\mathrm{H} \%$ \\
\hline $\mathrm{C} 12-1$ & $12.64(12.45)^{\mathrm{a}}$ & $75.68(76.27)$ \\
$\mathrm{C} 12-2$ & $12.11(11.93)$ & $74.81(74.79)$ \\
$\mathrm{C} 12-3$ & $11.94(11.71)$ & $73.64(74.18)$ \\
$\mathrm{C} 12-4$ & $11.71(11.59)$ & $73.52(73.84)$ \\
\hline $\mathrm{C} 14-1$ & $12.99(12.69)$ & $77.18(77.48)$ \\
$\mathrm{C} 14-2$ & $12.74(12.24)$ & $75.94(76.17)$ \\
$\mathrm{C} 14-3$ & $12.01(12.04)$ & $74.80(75.62)$ \\
\hline
\end{tabular}

${ }^{\mathrm{a}}$ Values in parentheses are calculated values. of C12-n and C14-n were measured on a Seiko DSC SSC560 differential scanning calorimeter. The standard heating rate was $5 \mathrm{~K} \mathrm{~min}^{-1}$, and a sample mass of $1.00 \mathrm{mg}$ was used. The melting temperatures were obtained from DSC peak and the heat quantity was computed from the DSC peak area and at a heating rate of $0.5 \mathrm{~K} \mathrm{~min}^{-1}$ using indium as the standard. The accuracy of the value was within $3 \%$.

\section{RESULTS AND DISCUSSION}

The DSC heating curves of the C12-n samples crystallized from a $0.1 \%$ heptane solution are shown in Figure 1. The monomer, dimer, trimer, and tetramer are perfectly separated and the sharpness of the peaks indicates the high purity of each C12-n sample. The heating curves exhibit a single peak, which implies that no solid-solid transitions occurred during heating. The sharpness of the DSC heating curves of C14-n was also similar to that of C12-n. The thermodynamic data of these n-mers are listed in Table II. The melting temperatures of $\mathrm{C} 12-1, \mathrm{C} 12-2, \mathrm{C} 12-3$, and $\mathrm{C} 12-4$ were $52.8,71.6,80.3$, and $85.4^{\circ} \mathrm{C}$, respectively, which were about $20-30^{\circ} \mathrm{C}$ lower than those of corresponding alkanes with the same carbon number. For both C12-n and C14-n series polyester oligomers, the melting temperatures converged with increasing $\mathrm{n}$, respectively.

For the thermodynamic investigation of polymers, it is important to determine the enthalpy of fusion

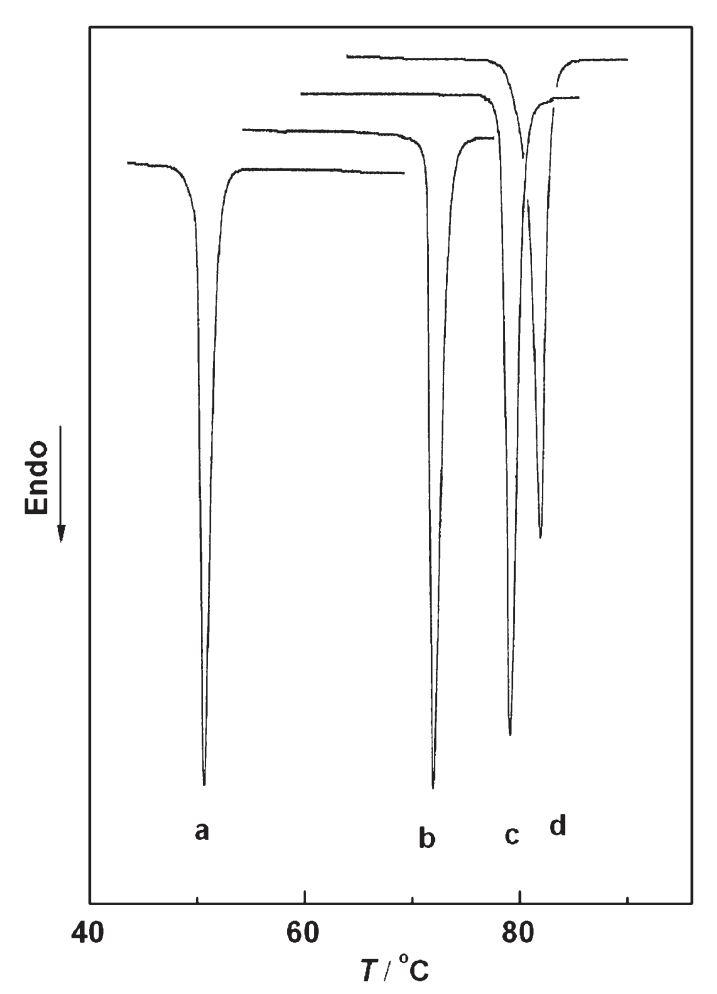

Figure 1. DSC heating curves of $\mathrm{C} 12-\mathrm{n}$ at $5 \mathrm{~K} \mathrm{~min}^{-1}$; a, C12-1; b, C12-2; c, C12-3; d, C12-4. 
Table II. Thermodynamic properties of model compounds for biodegradable aliphatic polyesters

\begin{tabular}{cccc}
\hline series - n mer & $T_{\mathrm{m}} /{ }^{\circ} \mathrm{C}$ & $\Delta H / \mathrm{kJ} \mathrm{mol}^{-1}$ & $\Delta S / \mathrm{JK}^{-1} \mathrm{~mol}^{-1}$ \\
\hline $\mathrm{C} 10-1$ & 38.0 & 87.0 & 279 \\
$\mathrm{C} 10-2$ & 59.2 & 162 & 487 \\
$\mathrm{C} 10-3$ & 69.4 & 227 & 664 \\
$\mathrm{C} 10-4$ & 75.3 & 288 & 827 \\
\hline $\mathrm{C} 12-1$ & 52.8 & 128 & 392 \\
$\mathrm{C} 12-2$ & 71.6 & 213 & 617 \\
$\mathrm{C} 12-3$ & 80.3 & 307 & 870 \\
$\mathrm{C} 12-4$ & 85.4 & 392 & 1092 \\
\hline $\mathrm{C} 14-1$ & 64.3 & 159 & 471 \\
$\mathrm{C} 14-2$ & 81.6 & 255 & 727 \\
$\mathrm{C} 14-3$ & 89.0 & 366 & 1011 \\
\hline
\end{tabular}

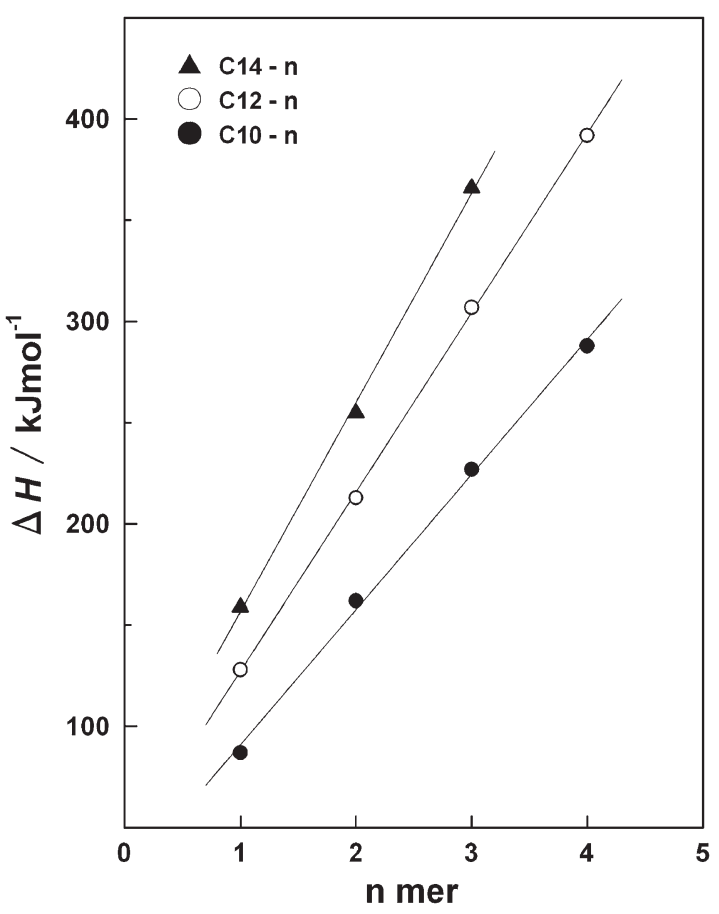

Figure 2. Dependence of heat of fusion of Cm-n on $n$.

$\Delta h$ or entropy of fusion $\Delta s$ for every repeating unit. However, an accurate determination of $\Delta h$ or $\Delta s$ is usually difficult in the case of polymers because they lack perfect crystallinity. In comparison, the model compound exhibits perfect crystallinity and a constant molecular weight, thus permitting an accurate determination of its $\Delta h$ or $\Delta s$, provided the effect of the end group is evaluated correctly. Figure 2 shows the degree of polymerization dependence of the enthalpies of fusion for the C10-n, C12-n, and C14-n series. The obtained linear functions are expressed as

$$
\begin{aligned}
& \Delta H=66.8 \mathrm{n}+24.0^{11} \\
& \Delta H=88.6 \mathrm{n}+38.5 \\
& \Delta H=103 \mathrm{n}+53.0
\end{aligned}
$$

for the C10-n, C12-n, and C14-n series, respectively.

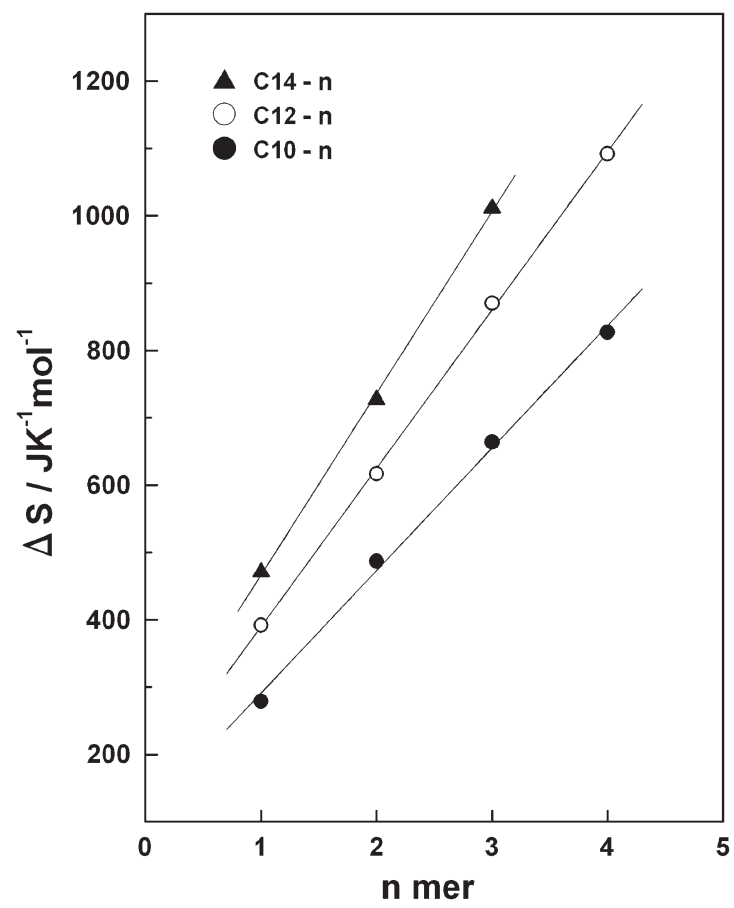

Figure 3. Dependence of entropy of fusion of Cm-n on $n$.

These equations demonstrate the additivity of the contributions of the monomer units (M) and terminal groups (T). Therefore, eqs 1,2 , and 3 can be rewritten as $\Delta H=\mathrm{n} \Delta h+\Delta h_{\mathrm{t}}$, where $\Delta h$ is the enthalpy change of fusion per repeating unit and $\Delta h_{\mathrm{t}}$ is the end-group contribution to the enthalpy change of fusion. ${ }^{17}$

Figure 3 shows the dependence of the entropies of fusion $\Delta S$ on $\mathrm{n}$ for the $\mathrm{C} 10-\mathrm{n}, \mathrm{C} 12 \mathrm{-n}$, and $\mathrm{C} 14-\mathrm{n}$ series. From $\Delta S=\Delta H / T_{\mathrm{m}}, \Delta S$ was calculated. The obtained linear functions are expressed as

$$
\begin{aligned}
& \Delta S=182 \mathrm{n}+109^{11} \\
& \Delta S=235 \mathrm{n}+155 \\
& \Delta S=270 \mathrm{n}+196
\end{aligned}
$$

for the C10-n, C12-n, and C14-n series, respectively. These equations also demonstrate the additivity of the contributions of the monomer units and terminal groups.

The melting point of polymers changes significantly depending on the crystallization and measurement conditions. Therefore, a quantity that does not depend on the preparation and measurement conditions of the sample must be used so that the melting point of the polymer can be treated as a thermodynamic quantity. In the case of melting point, only the melting point of a perfect crystal polymer satisfies this condition. The melting point of a paraffin crystal consisting of an extended molecular chain increases with the chain length (carbon number), and it approaches the equilibrium melting point $\left(141^{\circ} \mathrm{C}\right)$ of polyethylene. This is 
shown by the next empirical formula. The equation $T_{\mathrm{m}}=414.3(\mathrm{n}-1.5) /(\mathrm{n}+5.0)$ is presented as an accurate description of the melting temperature of all $n$-alkanes above $n$ - $\mathrm{C}_{44} \mathrm{H}_{90} \cdot{ }^{1}$

From eqs 2 and 5 , the equation for the melting temperature of C12- $\mathrm{n}$ is $T_{\mathrm{m}}=377(\mathrm{n}+0.435) /(\mathrm{n}+$ $0.660)$. From this equation, the equilibrium melting temperature, $T_{\mathrm{m}}{ }^{0}$, of poly(dodecamethylene dodecanoate) was obtained as $104^{\circ} \mathrm{C}(377 \mathrm{~K})$. Similarly, from eqs 3 and 6 , the equation for the melting temperature of C14-n is $T_{\mathrm{m}}=381(\mathrm{n}+0.515) /(\mathrm{n}+0.726)$. From this equation, the equilibrium melting temperature $T_{\mathrm{m}}{ }^{0}$ of poly(tetradecamethylene tetradecanoate) was obtained as $108^{\circ} \mathrm{C}(381 \mathrm{~K})$.

The enthalpy change of fusion per repeating unit obtained for the $\mathrm{C} 10, \mathrm{C} 12$, and $\mathrm{C} 14$ series polyesters are $66.8 \mathrm{~kJ} \mathrm{~mol}^{-1}$ from eq $1,88.6 \mathrm{~kJ} \mathrm{~mol}^{-1}$ from eq 2 , and $103 \mathrm{~kJ} \mathrm{~mol}^{-1}$ from eq 3 , respectively. The relationship between the enthalpy change of fusion per repeating unit, $\Delta h$, and the number of carbon atoms in the chain, $\mathrm{m}$, can be expressed linearly as follows:

$$
\Delta h=9.05 \mathrm{~m}-22.5
$$

Similarly, the relationship between the entropy change of fusion per repeat unit, $\Delta s$, and the number of carbon atoms in the chain, $\mathrm{m}$, can be expressed linearly as follows:

$$
\Delta s=22 \mathrm{~m}-35
$$

Consequently, a combination of eqs 7 and 8 yields eq 9, which relates the equilibrium melting temperature $T_{\mathrm{m}}{ }^{0}$ and $\mathrm{m}$ as follows:

$$
T_{\mathrm{m}}{ }^{0}=411(\mathrm{~m}-2.48) /(\mathrm{m}-1.59)
$$

The melting temperature of $\mathrm{C} 30$ polyester with $\mathrm{m}=30$ is $113{ }^{\circ} \mathrm{C} .{ }^{18}$ The calculated equilibrium melting temperature is $125^{\circ} \mathrm{C}$, which is $12^{\circ} \mathrm{C}$ higher than the value of the polymer. We can easily calculate the approximate equilibrium melting temperature of aliphatic polyesters with $\mathrm{m} \geqq 10$ using eq 9 , and this can be compared with the value expected for completely crystal materials.

\section{REFERENCES}

1. M. G. Broadhurst, J. Res. Nat. Bur. Std., 67A, 233 (1963).

2. M. G. Broadhurst, J. Res. Nat. Bur. Std., 70A, 481 (1966).

3. J. D. Hoffman, L. J. Ross, G. S. Ross, and J. I. Lauritzen, J. Res. Nat. Bur. Std., 79A, 671 (1975).

4. H. Illers and H. Hendus, Makromol. Chem., 113, 1 (1968).

5. B. Wunderlich, "Macromolecular Physics," Academic Press, New York, 1980, vol. 3, p 26.

6. K. Yamada, M. Hikosaka, A. toda, S. Yamazaki, and K. Tagashira, Macromolecules, 36, 4790 (2003).

7. M. Al-Hussein and G. Stroble, Macromolecules, 35, 1672 (2002).

8. C. Wang, Y.-W. Cheng, Y.-C. Hsu, and T.-L. Lin, J. Polym. Sci., Part B: Polym. Phys., 40, 1626 (2002).

9. M. J. Jenkins, Y. Cao, and S. N. Kukureka, Polym. Adv. Technol., 17, 1 (2006).

10. Z. Gan, H. Abe, H. Kurokawa, and Y. Doi, Biomacromolecules, 2, 605 (2001).

11. Y. Ogawa, M. Okeda, and N. Matsumoto, Polym. J., 38, 85 (2006).

12. J. Brandrup and E. H. Immergut, "Polymer Handbook," 3rd ed., John Wiley \& Sons, New York, N.Y., 1989.

13. P. A. Aylwin and R. H. Boyd, Polymer, 25, 323 (1984).

14. T. Kanamoto and K. Tanaka, J. Polym. Sci., Part A-2, 9, 2043 (1971).

15. E. Amelin, M. T. Casas, and J. Puiggali, Polymer, 42, 5695 (2001).

16. E. Amelin, A. Almontassir, L. Franco, and J. Puiggali, Macromolecules, 35, 3630 (2002).

17. Y. Ogawa, Polym. J., 28, 289 (1996).

18. I. Cho and K. Lee, Macromol. Chem. Phys., 198, 861 (1997). 